\title{
The capBCA locus is required for intracellular growth of Francisella tularensis LVS
}

\author{
Jingliang Su', Rexford Asare ${ }^{2}$, Jun Yang ${ }^{3}$, Manoj Kumar Mohan Nair ${ }^{3}$, Joseph E. Mazurkiewicz ${ }^{4}$, \\ Yousef Abu-Kwaik ${ }^{2}$ and Jing-Ren Zhang ${ }^{3,5 *}$
}

Key Laboratory of Zoonosis of Ministry of Agriculture, College of Veterinary Medicine, China Agricultural University, Beijing, China

2 Department of Microbiology and Immunology, College of Medicine, Louisville, KY, USA

${ }^{3}$ Center for Immunology and Microbial Disease, Albany Medical College, Albany, NY, USA

${ }^{4}$ Center for Neuropharmacology and Neuroscience, Albany Medical College, Albany, NY, USA

${ }^{5}$ Center for Infectious Disease Research, School of Medicine, Tsinghua University, Beijing, China

\section{Edited by:}

Anders Sjostedt, Umeå University, Sweden

\section{Reviewed by:}

Jason F. Huntley, University of Toledo, USA

Rachel Elizabeth Dean, Defence

Science and Technology Laboratory, UK

${ }^{*}$ Correspondence:

Jing-Ren Zhang, Center for Infectious

Disease Research, School of Medicine,

Tsinghua University, Beijing 100084,

China.

e-mail: zhanglab@tsinghua.edu.cn
Francisella tularensis is the causative agent of tularemia and a category A bioterrorism agent. The molecular basis for the extreme virulence of $F$. tularensis remains unclear. Our recent study found that $\operatorname{cap} B C A$, three neighboring genes, are necessary for the infection of $F$. tularensis live vaccine strain (LVS) in a respiratory infection mouse model. We here show that the capBCA genes are necessary for in vivo growth of $F$. tularensis LVS in the lungs, spleens, and livers of BALB/c mice. Unmarked deletion of capBCA in type A strain Schu S4 resulted in significant attenuation in virulence although the level of the attenuation in Schu S4 was much less profound than in LVS. We further demonstrated that CapB protein is produced at a low level under the in vitro culture conditions, and cap $B$ alone is necessary for in vivo growth of $F$. tularensis LVS in the lungs of $\mathrm{BALB} / \mathrm{c}$ mice. Finally, deletional mutations in $\operatorname{cap} B$ alone or capBCA significantly impaired intracellular growth of $F$. tularensis LVS in cultured macrophages, thus suggesting that the capBCA genes are necessary for intracellular adaptation of $F$. tularensis. The requirement of this gene locus in intracellular adaption at least in part explains the significant attenuation of F. tularensis capBCA mutants in virulence.

Keywords: Francisella tularensis, capBCA, fitness, virulence, macrophage

\section{INTRODUCTION}

Francisella tularensis is a Gram-negative intracellular bacterium and causative agent of tularemia in humans and many other species (Sjostedt, 2007). There are four F. tularensis subspecies or biotypes: tularensis (type A), holarctica (type B), mediasiatica, and novicida. All $F$. tularensis subspecies are able to cause lethal infection in mice, but only the strains of types A and B are mostly associated with human disease (Keim et al., 2007). F. tularensis live vaccine strain (LVS) is a type B derivative. LVS is relatively avirulent in humans but causes a lethal infection in mice that highly resembles human tularemia (Eigelsbach and Downs, 1961; Anthony and Kongshavn, 1987). The infection can be transmitted by inhalation of $F$. tularensis-containing aerosols, bites of blood-sucking insects, handling of infected animal carcasses, and consumption of contaminated food or water. Respiratory tularemia has attracted the most attention because inhalation of as few as 10-50 live organisms of $F$. tularensis type A can cause disease and the mortality rate can be $>30 \%$ by the respiratory route in the absence of antibiotic therapy (McCrumb, 1961). As a result, F. tularensis type A strains are listed as a category A potential agent of bioterrorism (Dennis et al., 2001).

Francisella tularensis is able to infect a range of cell types, but its primary target during infection appears to be the macrophage (Clemens and Horwitz, 2007). The pathogenic mechanisms of $F$. tularensis infection are poorly understood. The extraordinary infectivity of $F$. tularensis is correlated with its efficient uptake, survival, and replication within host cells (Clemens and Horwitz, 2007). The ability of $F$. tularensis to propagate intracellularly is enhanced by the failure of lysosomes to fuse with the phagosome (Anthony et al., 1991) and the lack of stimulation of a respiratory burst (Wilson et al., 1980; Fortier et al., 1994). F. tularensis appears to bind host cells by interacting with complement receptors (Clemens et al., 2005). After entry into macrophages, the spacious phagosomes are rapidly modified to a tight phagosome (Clemens et al., 2005). In the initial phase of intracellular infection, $F$. tularensis resides in the membrane-bound phagosomes of macrophages and does not appear to replicate (Golovliov et al., 2003; Clemens et al., 2004; Santic et al., 2005a). Replication occurs once the bacterium escapes into the cytosol when the phagosomal membranes are damaged (Golovliov et al., 2003; Clemens et al., 2004; Santic et al., 2005a). The mechanisms for bacterial escape into the cytosol remain to be defined. It is also unclear how F. tularensis disseminates from infected host cells to uninfected cells in vivo. It is thought that $F$. tularensis-infected macrophages are lysed by bacterium-induced apoptosis (Lai et al., 2001; Lai and Sjostedt, 2003).

The virulence determinants of $F$. tularensis are not well understood (Barker and Klose, 2007). The lipopolysaccharide (LPS) of F. tularensis has been extensively studied because of its unusually low toxicity in vitro and in vivo and potential as a vaccine component (Sandstrom et al., 1992; Ancuta et al., 1996). Several bacterial proteins have recently been implicated in F. tularensis pathogenesis. These include AcpA (Mohapatra et al., 2007), MglA/ MglB (Baron and Nano, 1998), and the proteins encoded by the 
iglABCD intracellular growth operon (Nano et al., 2004). Recent whole-genome screens in F. tularensis strains Schu S4 (Qin and Mann, 2006; Kadzhaev et al., 2009), LVS (Maier et al., 2007; Su et al., 2007; Schulert et al., 2009), and U112 (Tempel et al., 2006; Weiss et al., 2007; Kraemer et al., 2009; Ahlund et al., 2010) have identified a large number of bacterial genes that are involved in $F$. tularensis growth in cultured macrophages and host tissues. Our recent study revealed that the capBCA genes of $F$. tularensis strain LVS are necessary for bacterial growth in the lungs of mice (Su et al., 2007). Growth as used here refers to the bacterial load in host tissues, which reflects the net outcome of bacterial replication and survival in the context of host defense.

In this study, we sought to understand how the capBCA locus contributes to $F$. tularensis pathogenesis. The in vivo growth kinetics of LVS and the isogenic capBCA mutants were determined in the lungs, spleens, and livers of infected BALB/c mice at various stages of infection. Unmarked deletion of $c a p B C A$ was generated to assess the significance of this gene locus in the virulence of type A virulent strain Schu S4. We further characterized the expression of capB and its impact on F. tularensis pathogenesis. Finally, the contribution of capBCA to intracellular growth of F. tularensis was evaluated in cultured macrophage lines. Our results suggest that the capBCA genes contribute to the virulence and pathogenesis of F. tularensis at least in part through enhancing bacterial intracellular adaptation.

\section{MATERIALS AND METHODS BACTERIAL STRAINS AND CHEMICAL REAGENTS}

Francisella tularensis LVS and its derivatives were cultured as described previously (Su et al., 2007). When necessary, kanamycin $(10 \mu \mathrm{g} / \mathrm{ml})$ or hygromycin $(200 \mu \mathrm{g} / \mathrm{ml})$ was added in the broth and agar media for selection purposes. F. tularensis Schu S4, originally isolated from a human case of tularemia (Eigelsbach et al., 1951), was obtained from the U.S. Army Medical Research Institute for Infectious Diseases (Frederick, MD, USA; Malik et al., 2007). The culture media and conditions for Schu S4 strain are the same as for LVS. Escherichia coli strains were grown in Luria-Bertani (LB) broth or on LB agar plates in the presence or absence of ampicillin $(100 \mu \mathrm{g} / \mathrm{ml})$, kanamycin $(50 \mu \mathrm{g} / \mathrm{ml})$, and hygromycin $(200 \mu \mathrm{g} / \mathrm{ml})$. All ingredients for bacterial culture media and other chemicals used in this work were obtained from Sigma (St. Louis, MO, USA) unless otherwise stated.

\section{SITE-DIRECTED MUTAGENESIS IN $\boldsymbol{F}$. TULARENSIS}

Unmarked in-frame deletional mutations were generated in the capBCA locus of strains LVS and Schu S4 by allelic replacement and counterselection as described (Su et al., 2007). All genetic manipulations of strain Schu S4 were performed with the approval of the Centers for Disease Control and Prevention (CDC) in a CDC-certified ABSL-3/BSL-3 facility at Albany Medical College. The entire coding region of the capBCA genes was deleted in Schu S4 using the conjugative plasmid pST937. pST937 was previously used to generate an unmarked deletion in capBCA of LVS (Su et al., 2007). capB was deleted in LVS in a similar manner with a few modifications. An 814-bp fragment downstream of $c a p B$ was PCR amplified from LVS genomic DNA using primers Pr1073 (5'-TACGAGAATTCTATAGTTTTAAGATTAAACAGGAGAAA-3') and Pr1074 (5'-CTTGTCTCGAGCATATTTGGATTAACCGAAG ACC-3'). This fragment was digested with EcoRI and XhoI and cloned behind the $5^{\prime}$ fragment of $c a p B$ in plasmid pST933 (Su et al., 2007). The entire construct was subcloned into the EcoRV site of a suicide plasmid pMP590 (LoVullo et al., 2006), resulting in the plasmid pMP590:: $\triangle$ capB or pST968. We chose pMP590 to delete $c a p B$ because of its better amenability in DNA cloning (partially due to its smaller size relative to pomp) and transformation (electroporation instead of conjugation for pDMK).pST968 was transferred into LVS by electroporation and selected for kanamycin resistance $(10 \mu \mathrm{g} /$ $\mathrm{ml}$ ) as described (LoVullo et al., 2006). To remove the inserted plasmid and generate desirable capB deletion, the kanamycin resistant transformants were streaked on chocolate agar plates containing $5 \%(\mathrm{w} / \mathrm{v})$ sucrose. The sucrose-resistant colonies were further screened for the loss of kanamycin resistance. The resulting clones were examined for the $c a p B$ deletion by PCR amplification using the flanking primers Pr896 (5'-AGCTGCACCTGAGTTATTTGAT-3') and Pr901 (5'-AAATGCAAATGCGTCGTTA-3'). The capB deletion was finally confirmed by DNA sequencing in strain ST1092, one of the resultant $\Delta c a p B$ mutants. ST1092 retains the sequence encoding the nine $\mathrm{N}$-terminal amino acids of CapB. The lack of the CapB protein in the $\triangle c a p B$ strains was assessed by Western blot using a mouse anti-CapB antiserum as described in western blot. The resultant strain ST1092 was selected for further characterization.

\section{COMPLEMENTATION OF CAPB DELETION}

The capB deletion in strain ST1092 was in trans complemented with an E. coli-Francisella shuttle plasmid pST1032 containing the intact $c a p B$ gene as described previously (Su et al., 2007). capB in pST1032 was driven by the Francisella groEL. pST1032 was electroporated into strain ST1092 and selected with $200 \mu \mathrm{g} / \mathrm{ml}$ hygromycin, resulting in strain ST1104. Production of the CapB protein in the complemented strains was assessed by western blot using a mouse antiserum against glutathione $S$ transferase (GST)-CapB as described in Section "Antibodies and Western blotting."

\section{GST-CAPB FUSION PROTEIN EXPRESSION}

A recombinant CapB was expressed as a fusion protein with the GST essentially as described (Lu et al., 2006). capB was amplified from the genomic DNA of strain LVS with primers Pr885 (5'-ATCCTGAATTCGGATCCATATTTTCTCCTGTTT- ${ }^{\prime}$ ') and Pr1175 (5'-ACTAGACCCGGGAACTACTTTGGATTTTTGGTTA ATTG-3'). This fragment was cloned into the $X m a I / E c o R I$ site of the pGEX-2T expression vector (GE Healthcare Bio-Science, Piscataway, NJ, USA) in E. coli strain BL-21 (DE3). The resultant E. coli strain was processed to produce and purify a GST fusion protein (designated GST-CapB) by affinity chromatography with the Glutathione Sepharose 4 Fast Flow resins (GE Healthcare Bio-Sciences) according to the supplier's instructions. Protein concentration was determined by the Bio-Rad Protein Assay kit (Bio-Rad, Hercules, CA, USA) and analyzed by SDS-PAGE as described (Lu et al., 2006).

\section{ANTIBODIES AND WESTERN BLOTTING}

Antiserum against the F. tularensis CapB was raised with the GSTCapB fusion protein as described (Zhang et al., 1997). Female $\mathrm{BALB} / \mathrm{c}$ mice (6-8 weeks old) were immunized with purified 
GST-CapB every 2 weeks via the subcutaneous route for a total of three immunizations. The immunogen for each immunization consisted of $25 \mu \mathrm{g}$ GST-CapB in $100 \mu$ sterile phosphate-buffer saline (PBS) and $100 \mu \mathrm{l}$ alum (Rehydrogel Low Viscosity Gel; Reheis, Berkeley Heights, NJ, USA) as described (Sun et al., 2004). Western blotting of F. tularensis proteins was performed with an enhanced chemiluminescence (ECL) Western Blot Kit (Pierce, Rockford, IL, USA) according to the supplier's instructions. The GST-CapB antiserum and peroxidase-conjugated goat anti-mouse IgG antibody (Bio-Rad laboratories, Hercules, CA, USA) were used at a dilution of 1:1000 and 1:5000, respectively.

\section{MOUSE INFECTIONS}

Infection experiments with F. tularensis LVS and its derivates were carried out in BALB/c mice as described (Su et al., 2007). All animal infection experiments were in compliance with the guidelines of the Institutional Animal Care and Use Committee at Albany Medical College. To prepare the F. tularensis inocula, frozen stocks of LVS and the isogenic capBCA mutants were individually diluted in PBS based on predetermined colony forming unit (CFU) values. Each preparation was serially diluted in PBS and plated to assess the actual CFUs of each inoculum immediately prior to the mouse infection experiments. Each inoculum was intranasally inoculated into groups of mice (female, 6-8 weeks old). Infected mice were sacrificed at various time points post-infection. The lungs, liver, and spleen were aseptically removed and processed to determine the CFU levels of LVS and the mutants in each organ as described (Su et al., 2007). To determine the virulence levels of the $\triangle$ capBCA mutants in the LVS and Schu S4 backgrounds, groups of five mice were intranasally infected with serial dilutions of the wild type and isogenic $\triangle c a p B C A$ strains. Infected mice were monitored daily for signs of morbidity and mortality for 21 days. Infection experiments with Schu S4 and all of its derivatives were carried out as described for strain LVS with the exception that all of the experiments associated with Schu S4 were performed and contained in a CDC-certified ABSL-3/BSL-3 facility at Albany Medical College.

To test the immuno-protection of $\triangle c a p B C A$ mutants, groups of five BALB/c mice were inoculated intranasally with different dosages of ST938. Mice injected with sterile PBS were used as control. Three weeks after immunization, each mouse was challenged intranasally with 40,000 CFU of LVS. Infected mice were monitored daily for clinical signs and mortality for 21 days.

\section{HISTOPATHOLOGY}

$\mathrm{BALB} / \mathrm{c}$ mice were intranasally infected with $\mathrm{F}$. tularensis LVS or isogenic mutants as described above. Mice, along with uninfected controls, were sacrificed to excise the lungs, liver, and spleen at day 7. The organs were fixed in 10\% neutral-buffered formalin, processed using standard histological methods to obtain 5 - $\mu$ m-thick paraffin sections, and stained with H\&E as described (Baron et al., 2007).

\section{MACROPHAGE INFECTION}

The human monocytic cell line U937 (ATCC CRL-1593.2) and mouse alveolar macrophages $\mathrm{MH}-\mathrm{S}$ cell line (ATCC CRL-2019) were obtained from the American Type Culture Collection (Manassas, VA, USA). U937 cells were maintained in Iscove's modified Dulbecco's medium (IMDM) supplemented with 10\% fetal bovine serum at $37^{\circ} \mathrm{C}, 5 \% \mathrm{CO}_{2}$; $\mathrm{MH}-\mathrm{S}$ cells were cultured in RPMI 1640 medium containing 10\% (v/v) fetal bovine serum and $0.05 \mathrm{mM} 2$-mercaptoethanol at $37^{\circ} \mathrm{C}$. Intracellular levels of F. tularensis were assessed out as described (Santic et al., 2005b). Briefly, $2.5 \times 10^{5}$ macrophages were cultured in 24-well plates (Hyclone, Logan, UT, USA) to approximately $80 \%$ confluency. The $F$. tularensis LVS derivatives were grown in $\mathrm{MHB}$ broth to $\mathrm{OD}_{600} \sim 1.2\left(\sim 3 \times 10^{9} \mathrm{CFUs} / \mathrm{ml}\right)$, pelleted by centrifugation, and resuspended in pre-warmed RPMI1640 to $\mathrm{OD}_{600} \sim 0.2$ $\left(\sim 5 \times 10^{8} \mathrm{CFUs} / \mathrm{ml}\right)$. After brief rinse with PBS, macrophages were infected with the bacterial suspensions at a multiplicity of infection (MOI) of 100 (bacterium vs. macrophage) at $0 \mathrm{~h}$. After $2 \mathrm{~h}$ of incubation at $37^{\circ} \mathrm{C}$, the unbound bacteria were removed from the wells by washing with PBS. Extracellular bacteria were killed by incubation with the cell culture medium containing gentamicin $(50 \mu \mathrm{g} / \mathrm{ml})$ for $1 \mathrm{~h}$ at $37^{\circ} \mathrm{C}$. The cells were extensively rinsed to remove residual gentamicin and then cultured without antibiotic. To monitor bacterial uptake and replication, the culture medium of infected macrophages was moved to sterile tubes to lyse the cells at 3,24, and $48 \mathrm{~h}$ post-infection with pre-chilled water. The medium and lysates from each well were combined, diluted with sterile PBS, and spread onto chocolate agar plates for CFU counts. Each infection experiment was repeated at least three times.

\section{FLUORESCENCE AND ELECTRON MICROSCOPY}

For fluorescence microscopy, U937 macrophages were infected with F. tularensis LVS as described previously (Santic et al., 2005a). Briefly, differentiated U937 cells on 12-mm-diameter circular glass coverslips (Fisher Scientific, Pittsburgh, PA, USA) in 24-well culture plates were infected with LVS and its isogenic mutants at MOI of 10 for $1 \mathrm{~h}$. To synchronize the infection, infected cells were centrifuged at $150 \times g$ for $5 \mathrm{~min}$ before incubation at $37^{\circ} \mathrm{C}$ in $5 \% \mathrm{CO}_{2}$. After $1 \mathrm{~h}$ of incubation, infected cells were washed three times with $1 \times$ PBS followed by $1 \mathrm{~h}$ of gentamicin $(50 \mu \mathrm{g} / \mathrm{ml})$ treatment. Cells were then fixed in $4 \%$ paraformaldehyde for $30 \mathrm{~min}$. Paraformaldehyde was removed by washing the wells three times with PBS. The infected cells were permeabilized with 1\% Triton-X100 for the LAMP-1 experiment. For the Cathepsin D experiments, the cells were permeabilized with acetone for $5 \mathrm{~min}$ at $-20^{\circ} \mathrm{C}$. Samples were stained with F. tularensis polyclonal antibody (1:4,000 dilution) and mouse monoclonal anti-LAMP-1 (H4B3; 1:500 dilution; Hybridoma Gene Bank) or anti-Cathepsin D (BD transduction; 1:500 dilution). Alexa fluor 594-conjugated anti-mouse secondary antibody (1:500 dilution) was used to stain the LAMP-1 and Cathepsin D. Alexa fluor 488-conjugated secondary antibody (1:500 dilution) was used to stain F. tularensis. Co-localization of bacteria with LAMP-1 and Cathepsin D was analyzed with FV1000 Olympus confocal microscope as described previously (Santic et al., 2005a,b, 2008). The bacteria associated with phagosomes and phagolysosomes were quantified by enumerating F. tularensis co-localized with LAMP-1/ Cathepsin D out of the total bacteria in 100 infected cells from more than 10 different fields for each strain. Each experiment was repeated at least once.

For electron microscopy, U937 macrophages growing in 6-well tissue culture plates were inoculated with $F$. tularensis as described above. Twenty-four hours post-inoculation, the wells were washed with $0.1 \mathrm{M} \mathrm{Na}$ Cacodylate buffer, $\mathrm{pH} 7.3$ and incubated for $1 \mathrm{~h}$ with 
a solution containing $2.5 \%$ glutaraldehyde/4\% formaldehyde in $0.1 \mathrm{M} \mathrm{Na}$ Cacodylate, $\mathrm{pH}$ 7.3. Following washing with Cacodylate buffer, the cells were post-fixed with $1.0 \%$ osmium tetroxide in $0.1 \mathrm{M} \mathrm{Na}$ Cacodylate buffer, $\mathrm{pH} 7.3$ for $1 \mathrm{~h}$. The monolayers were washed with normal saline, and scraped with a Costar cell scraper into normal saline and gently pelleted by centrifugation. The pellets were dehydrated in a graded Ethanol series and embedded in LR White medium (Polysciences, Inc.). Ultrathin sections were collected onto Formvar-coated grids, stained with uranyl acetate and lead citrate. Specimens were viewed and photographed with a JEOL 100CX transmission electron microscope using Kodak electron microscope film.

\section{STATISTICAL ANALYSIS}

A log-rank test was used to determine the level of significance for the Kaplan-Meier survival analyses. All other results were expressed as mean \pm SEM and comparisons between the groups were made using Student's $t$ test. Differences between control and experimental groups were considered significant at $p<0.05$ levels.

\section{RESULTS}

\section{IN VIVO GROWTH KINETICS OF THE LVS capBCA MUTANTS}

In our previous study (Su et al., 2007), the LVS mutant lacking the capBCA genes $(\triangle c a p B C A)$ exhibited significantly impaired growth in the lungs of infected mice at day 7 post-intranasal inoculation. However, it was unclear whether the $c a p B C A$ genes are required at the earlier and/or later stages of F. tularensis infection. We thus determined the in vivo growth kinetics of $\triangle c a p B C A$ by assessing the levels of bacterial burdens in the lungs, kidneys, and livers of infected BALB/c mice on days $1,2,4,7,14$, and 21 post-intranasal inoculation.

To accurately determine the inoculation efficiency, we first determined bacterial loads in the lungs of infected mice immediately after intranasal inoculation. Mice infected with LVS or $\triangle$ capBCA (strain ST938) showed a similar level of bacteria ( $3 \times 10^{3}$ CFUs) in the lungs $1 \mathrm{~h}$ post-intranasal inoculation of $5 \times 0^{3} \mathrm{CFUs}$ (day 0 ; Figure 1A). This indicated that $\triangle c a p B C A$ was effectively inoculated into the lungs of mice at a similar efficiency as the parent strain LVS. $\triangle$ capBCA displayed a significant growth deficiency in the lungs throughout the entire test period (Figure 1A). In sharp contrast to a 15.1-fold growth of LVS in the lungs of infected mice in initial $24 \mathrm{~h}$, the number of $\triangle c a p B C A$ dropped by $75 \%$ during the same infection period, indicating that the capBCA locus is required for bacterial growth in the initial phase of LVS infection. At days 2 and 4 , both LVS and $\triangle c a p B C A$ exhibited substantial growth, but the numbers of $\triangle c a p B C A$ were significantly lower when compared with that of LVS. At day 7, the bacterial levels of both LVS and $\triangle c a p B C A$ were reduced bacterial burdens, likely due to the onset of the adaptive immunity. By 9 days post-inoculation, all of the LVS-infected mice died, whereas $\triangle c a p B C A$-infected mice did not display any detectable sign of disease and remained disease-free throughout the 21-day infection period. Finally, $\triangle$ cap $B C A$ became undetectable from the lungs of the infected mice at days 14 and 21 .

We also assessed the dissemination of $\triangle c a p B C A$ from lung to spleen and liver in the same BALB/c mice as described in Figure 1A. As early as $24 \mathrm{~h}$ post-inoculation, LVS were readily detected in the spleens (2,430 CFUs in average) and livers (42,840 CFUs in average), whereas $\triangle c a p B C A$ was barely detectable in these distal organs until day 4 (Figures 1B,C). Similar to the kinetics of bacterial burden in the lungs, the numbers of $\triangle c a p B C A$ were significantly lower than those of LVS in the spleens and livers from days 1 to $7 . \triangle c a p B C A$ became undetectable in the livers of all infected mice on days 14 and 21. Interestingly, there were low levels of $\triangle$ capBCA detectable in the spleens of two and one mice (out of six) at days 14 and 21, respectively (see below for additional interpretations). We thus conclude that the capBCA genes are necessary for in vivo growth of $F$. tularensis LVS (bacterial replication and resistance to host killing).

\section{LD $_{50}$ AND IMMUNO-PROTECTION OF LVS $\triangle$ capBCA}

The persistent presence of $\triangle c a p B C A$ in the spleens (Figure 1B) raised the possibility that the mutant is capable of better priming the adaptive immunity against $F$. tularensis LVS. To test this notion, we first attempted to assess the attenuation level of $\triangle$ capBCA by determining the $\mathrm{LD}_{50}$. Groups of $\mathrm{BALB} / \mathrm{c}$ mice were intranasally infected with a wide range of bacterial doses $\left(4.5 \times 10^{2-7}\right.$ CFUs $)$. None of the infected mice showed any appreciable symptoms or died from the infection during the 6-week period of observation (data not shown), indicating the $\mathrm{LD}_{50}$ of the $\triangle$ capBCA mutant
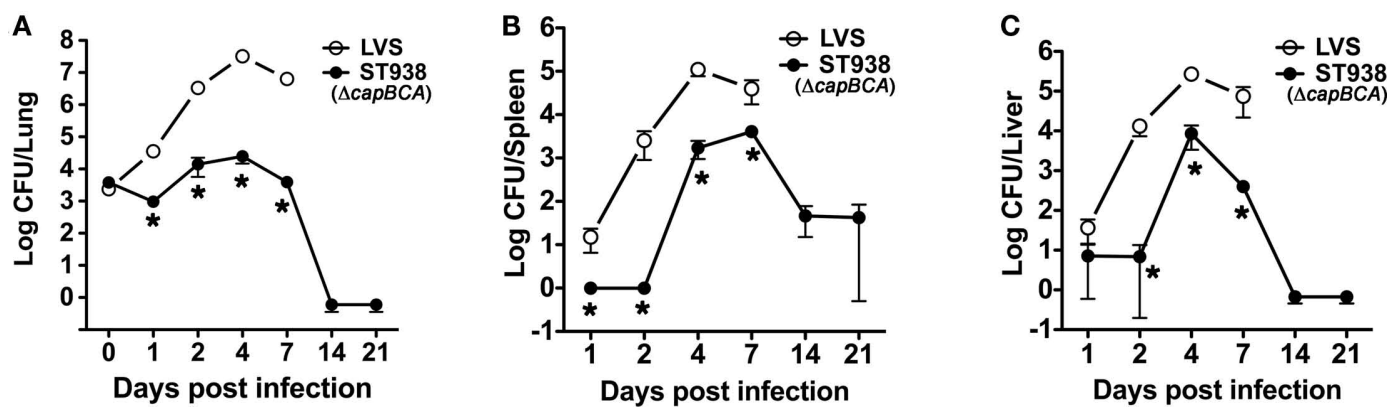

FIGURE 1 | In vivo growth of LVS $\triangle$ capBCA. (A) Bacterial burden in the lungs of BALB/c mice $(n=5)$ infected with LVS or isogenic $\triangle$ capBCA strain ST938 alone. Lung tissues were collected to determine the viable bacteria by plating various dilutions of tissue homogenates at days $0,1,2,4,7,14$, and 21 post-inoculation. Bars indicate the mean $\log _{10}$ CFU values \pm SEM. Asterisks indicate $p<0.05$ as determined by Student's $t$ test. (B) Bacterial burdens in the spleens of mice infected individually with LVS derivatives were determined as in (A). (C) Bacterial burdens in the livers of mice infected individually with LVS derivatives were determined as in (A) 
was $>4.5 \times 10^{7} \mathrm{CFU}$. LVS has an $\mathrm{LD}_{50}$ of $\sim 4 \times 10^{3}$ CFUs in this infection model (Duckett et al., 2005); all of mice infected with $\sim 8 \times 10^{3}$ CFUs of LVS died in the first 2 weeks of infection (data not shown). Therefore, LVS $\triangle a p B C A$ is avirulent in this BALB/c mouse model.

We next tested immuno-protection of $\triangle c a p B C A$ against infection of F. tularensis LVS. Groups of five BALB/c mice were intranasally infected (or immunized) with ST938 in a dose range of $4.5 \times 10^{2-7}$ CFUs. The mice were intranasally challenged with 40,000 CFUs of LVS (10 times of LVS LD Li $_{50}$ in this model) 3 weeks post-immunization. All of the five unimmunized mice (negative control) died within 9 days following LVS challenge (Table 1). Similarly, the majority $(80 \%)$ of the mice immunized with 450 CFUs of ST938 succumbed to LVS challenge. In contrast, all of the mice immunized with higher doses of ST938 $\left(4.5 \times 10^{3-7}\right.$ CFUs) did not show appreciable sign of illness after the challenge with 40,000 CFUs of LVS in the 4-week observation period (Table 1), indicating that $\triangle c a p B C A$ is able to induce strong adaptive immunity against infection of $F$. tularensis LVS even at relative low doses of immunization (e.g., $10^{3-4} \mathrm{CFUs}$ ). This result agrees with a recent report that an LVS $\Delta c a p B$ strain induces potent immunoprotection against LVS challenge (Jia et al., 2010). We further tested the immuno-protection potential of $\triangle c a p B C A$ against the challenges with type A virulent strain Schu S4 in a similar manner. None of the intranasal immunization doses $\left(4.5 \times 10^{3-7}\right.$ CFUs of strain ST938) conferred significant protection against intranasal challenge with 100 CFUs of Schu S4 (data not shown). The sharp difference in immuno-protection of LVS $\triangle$ capBCA against LVS and Schu S4 demonstrate the distinct requirements for protective immunity against infections of types A and B F. tularensis.

\section{IMPORTANCE OF CapBCA IN TYPE A F. TULARENSIS}

The gene sequence and organization of the capBCA locus are virtually identical between $F$. tularensis subsp. holarctica (type B) and subsp. tularensis (type A). We thus tested whether the capBCA genes are necessary for the virulence of $F$. tularensis type A virulent strain Schu S4. The coding sequence of the capBCA locus in Schu S4 was deleted by allelic replacement and counter selection as described in Section "Materials and Methods." As observed with the $\triangle c a p B C A$ mutants in LVS (Su et al., 2007), the Schu S4 $\triangle c a p B C A$ mutants did not show obvious growth defects under in vitro conditions (data not shown). ST965, one of the Schu S4 $\triangle c a p B C A$ mutants, was subjected to further characterization of its virulence in the lung infection mouse model. Since laboratory mice are extremely susceptible to Schu S4 infection (Malik et al.,

Table 1 | Protection of LVS $\triangle$ capBCA against lethal LVS infection.

\begin{tabular}{ll}
\hline Immunization dose (CFU) & Survived/total mice \\
\hline 0 & $0 / 5$ \\
$4.5 \times 10^{2}$ & $1 / 5$ \\
$4.5 \times 10^{3}$ & $5 / 5$ \\
$4.5 \times 10^{4}$ & $5 / 5$ \\
$4.5 \times 10^{5}$ & $5 / 5$ \\
$4.5 \times 10^{6}$ & $5 / 5$ \\
$4.5 \times 10^{7}$ & $5 / 5$
\end{tabular}

2007), the infection doses of the $\triangle c a p B C A$ mutant were accordingly adjusted. While all of mice infected with 16 CFUs of Schu S4 died by day 9 , the mortality rate of mice infected with ST965 was significantly reduced in a dose-dependent manner (Figure 2). In general, the attenuation of the Schu S4 $\triangle$ capBCA mutant was less pronounced than that of the LVS counterpart in this model. Michell et al. (2010) recently reported that deletion of capB in Schu S4 led to $>100$-fold attenuation in virulence in a subcutaneous infection model of $\mathrm{BALB} / \mathrm{c}$ mice. These findings thus indicated that the capBCA locus is necessary for the full virulence of human virulent F. tularensis type A strains.

\section{CHARACTERIZATION OF $\boldsymbol{F}$. TULARENSIS capB}

To gain more insight into the function(s) of the F. tularensis cap$B C A$ locus, we further characterized $c a p B$. The coding sequence of $c a p B$ in LVS was removed by allelic exchange. Three resulting strains (ST1092-4) were verified for the lack of $c a p B$ as determined by PCR amplification (Figure 3A) and DNA sequencing (data not shown). Primers Pr896/Pr901 were expected to produce amplicons of 2,177 bp in LVS and $991 \mathrm{bp}$ in $\Delta c a p B$ mutants ST1092-4. To determine the expression of the CapB protein, we also constructed a GST-CapB fusion protein in E. coli to generate an antiserum against $\mathrm{CapB}$ in mice. The F. tularensis $\mathrm{CapB}$ protein is predicted to contain 405 amino acids with the molecular mass of $44.9 \mathrm{kDa}$. As represented in Figure 3B, the antiserum reacted with a protein band of $44 \mathrm{kDa}$ in LVS, which was completely absent in the isogenic $\Delta c a p B$ mutant ST1092. The missing band in ST1092 was restored in trans by the shuttle plasmid pST1032 (strain ST1104). We thus concluded that the antiserum specifically detected the CapB protein. The CapB protein appears to be produced at a relatively low level under in vitro culture conditions because it was only detected when a large amount of the total bacterial lysates $\left(\sim 2 \times 10^{9} \mathrm{CFU}\right)$ was loaded in the protein gel. This was not due to a potential low titer of the antiserum because the antiserum readily detected CapB with $\sim 2 \times 10^{8} \mathrm{CFUs}$ of the complementation strain ST1104 (data not shown). Apparent overproduction of CapB in ST1104 was likely due to the strength of the Francisella groEL promoter and/or copy number of the

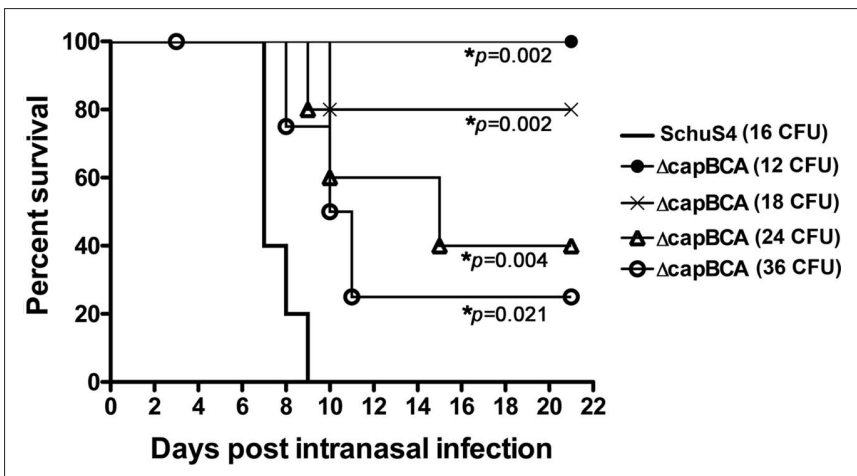

FIGURE 2 | Contribution of capBCA to the virulence of type A $F$ tularensis. BALB/c mice $(n=5)$ were intranasally infected with the indicated doses of Schu S4 or isogenic $\triangle c a p B C A$ mutant ST965. Survival was monitored for 21 days. The results are expressed as Kaplan-Meier curves and $p$ values determined using log-rank test. The data shown are a representative of two independent experiments. 

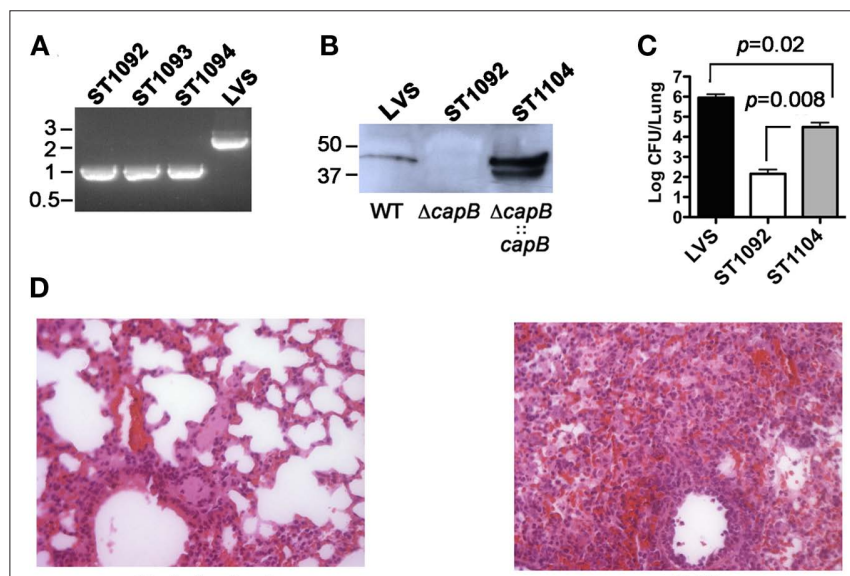

Uninfected
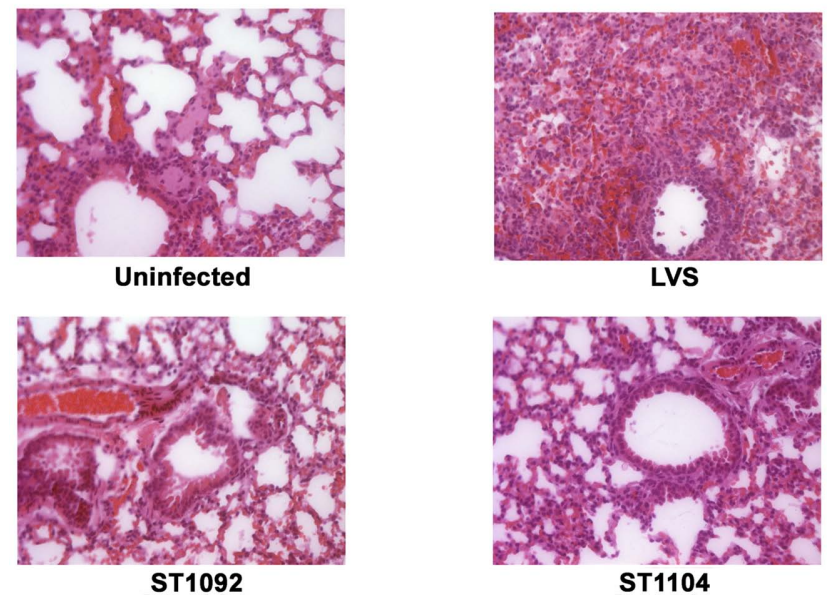

FIGURE 3 | CapB expression and its impact on in vivo growth of F tularensis. (A) Detection of the capB deletion by PCR. The sequence surrounding the $c a p B$ gene was amplified from the genomic DNA of LVS or three isogenic $\Delta c a p B$ clones (ST1092-4). The PCR products were separated in a $1 \%$ agarose gel and stained with ethidium bromide. The sizes of the DNA standards are indicated in kilobase. (B) Western blot detection of the $F$. tularensis CapB. Cell lysates of LVS derivatives representing $2 \times 10^{9} \mathrm{CFUs}$ were separated by SDS-PAGE, probed with the GST-CapB antiserum, and detected by an ECL method. (C) In vivo growth of the $F$. tularensis $\Delta$ capB mutant. BALB/c mice were infected individually with LVS (4,500 CFUs), ST1092 (5,100 CFUs), or ST1104 (4,800 CFUs) by intranasal inoculation. Bacterial levels in the lungs were assessed at day 7 as in Figure 1. (D) Lung histopathology of F. tularensis-infected mice. BALB/c mice were infected as in (C). Lung tissues were processed for H\&E staining at day 7 post-infection. Magnification $=20 \times$.

complementation construct as reported by Charity et al. (2007). A second band detected by the antiserum in ST1104 may represent a smaller isoform of the F. tularensis $\mathrm{CapB}$ as reported for the $B$. anthracis CapB (Makino et al., 1989).

We further performed infection experiments with the $\Delta c a p B$ mutant ST1092 and isogenic complementation strain ST1104. The $\Delta c a p B$ mutant was significantly deficient in in vivo growth at day 7 post-intranasal inoculation compared to the parent strain LVS (Figure 3C; Figure A1 in Appendix). The attenuation phenotype of ST1092 was partially in trans restored in complementation strain ST1104. The same capB complementation construct also showed partial complementation in the transposon mutant JS2512 in our previous study (Su et al., 2007). This could be due to instability of the shuttle plasmid during infection in the absence of antibiotic selection and/or inappropriate in trans expression level of the CapB protein. We also examined the impact of capB on $F$. tularensis pathogenesis by comparing histopathology of the lungs from BALB/c mice intranasally infected with either LVS or isogenic $\Delta c a p B$ mutants. In agreement with previous studies (Baron et al., 2007; Malik et al., 2007), the lungs of the LVS-infected mice had severe inflammation and tissue damage at day 7 postinfection as compared to the uninfected control (Figure 3D). In contrast, mice infected with ST1092 showed a relatively normal lung structure with little sign of inflammation. The lungs of mice infected with the $c a p B$ complementation strain ST1104 exhibited a low level of tissue infiltration but the overall structure was relatively normal. Together with the experimental data with $\triangle c a p B C A$ (Figure 1; Su et al., 2007), these results allowed us to conclude that $c a p B$ itself is necessary for the fitness of F. tularensis LVS. Our data are also consistent with a very recent study reporting that an LVS $\Delta c a p B$ mutant is severely attenuated in BALB/c mice (Jia et al., 2010).

\section{DEFICIENCY OF THE capBCA MUTANTS IN INTRA-MACROPHAGE GROWTH}

We sought to understand how the capBCA locus contributes to in vivo adaptation of $F$. tularensis. Since $F$. tularensis is a facultative intracellular pathogen, we tested whether the capBCA genes are required for intracellular growth of F. tularensis. We initially tested the intracellular infection of $\triangle c a p B$ and $\triangle c a p B C A$ in mouse $\mathrm{MH}-\mathrm{S}$ macrophages, because this is a commonly used alveolar macrophage model derived from BALB/c mice (Mbawuike and Herscowitz, 1989; Ibrahim-Granet et al., 2003). At the end of the gentamicin treatment (hour 0 ), $\triangle c a p B$ and $\triangle c a p B C A$ showed similar levels of the intracellular growth as the parent strain LVS (Figure 4A). Because F. tularensis does not appear to replicate in the first 3 h postinfection (Golovliov et al., 2003; Clemens et al., 2004; Santic et al., 2005a), the result indicated that capBCA locus is dispensable for the initial phase of intracellular infection (bacterial adherence and uptake). By 24 and $48 \mathrm{~h}$ post-inoculation, the macrophages infected with $\triangle c a p B$ or $\triangle c a p B C A$ showed significantly lower CFUs (approximately 14- to 22-fold reduction) as compared to the cells infected with LVS (Figure 4A). Noticeably, $\triangle c a p B$ and $\triangle c a p B C A$ behaved similarly in this assay, suggesting that $c a p B$ carries out an important function(s) in this locus. The growth defect of $\Delta c a p B$ was not due to the abnormal growth of the mutant in the culture medium because LVS and its capBCA derivatives showed obvious growth in the absence of macrophages under the same conditions (data not shown). The defect of $\Delta c a p B$ in intracellular growth was partially restored by in trans complementation (Figure $4 \mathrm{~A}, \Delta \mathrm{capB}:$ :capB). The complementation strain still exhibited significant deficiency (two- to threefold) in intracellular growth as compared to LVS, likely due to overexpression of $c a p B$ on the complementation construct (see Figure 3B). We were unsuccessful in our attempts to complement the entire capBCA locus due to technical difficulty in cloning the three genes in E. coli-Francisella shuttle vectors (data not shown).

We subsequently confirmed the impairment of $\triangle c a p B$ and $\triangle c a p B C A$ in intracellular growth using human U937 macrophages. Like in MH-S cells, the intracellular growth defect of $\triangle c a p B$ and $\triangle c a p B C A$ was only observed after the initial phase of infection (Figure 4B, hour 0). A noticeable difference between the $\mathrm{MH}-\mathrm{S}$ and U937 results is the marginal effect of in trans complementation construct on the intracellular growth phenotype of $\Delta c a p B$ in U937 cells (Figure 4B, $\Delta c a p B:: c a p B$ ). A very recent study by Jia et al. (2010) also showed that an LVS $\Delta c a p B$ mutant is significantly 

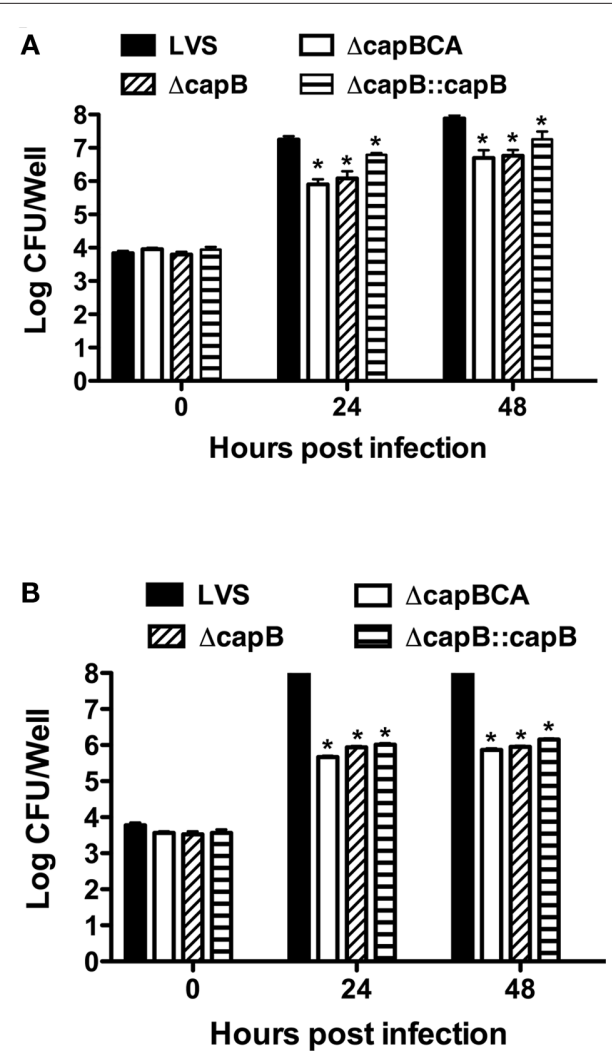

FIGURE 4 | Intracellular growth of $\boldsymbol{F}$ tularensis capBCA mutants. (A) Intracellular growth of LVS derivatives in MH-S macrophages. Macrophages were infected at a multiplicity of infection of $~ 100: 1$ (bacterium vs. macrophage) with LVS, isogenic $\triangle$ capBCA (strain ST938), $\Delta$ capB (strain ST1092), or complemented $\Delta c a p B$ ( $\Delta$ capB::capB, strain ST1104). Total bacteria per well were enumerated at the indicated time points. Statistic significance between LVS and its isogenic capBCA mutants ( $p>0.05$ ) was determined using Student's $t$ test. (B) Intracellular growth of LVS derivatives in U937 macrophages. The infection experiments were carried out and analyzed as in (A)

attenuated in intracellular growth in THP-1 macrophages. Together, these results demonstrate that the capBCA locus is required for intracellular growth of F. tularensis LVS.

\section{SUB-CELLULAR LOCALIZATION OF THE capBCA MUTANTS IN MACROPHAGES}

Previous studies indicate that $F$. tularensis transiently resides in a LAMP-1 and LAMP-2 positive phagosomes before escape into the cytosol for replication (Santic et al., 2010). The existing data have shown a correlation between escape into the cytosol and loss of LAMP-1/2 co-localization (Checroun et al., 2006; Bonquist et al., 2008; Asare and Abu Kwaik, 2010). Therefore, loss of co-localization with LAMP-1 and LAMP-2 has been used as an indicator for cytosolic localization of F. tularensis (Buchan et al., 2009). Based on the importance of the capBCA genes in F. tularensis intracellular growth (Figure 4), we reasoned that this locus might play a role in the phagosomal escape of the bacterium and/or arrest of phagosomal maturation. To test this possibility, we analyzed co-localization of $\triangle c a p B$ and $\triangle c a p B C A$ with LAMP-1 (a phagosomal marker) and Cathepsin D (a lysosomal marker) in U937 macrophages by immunofluorescence microscopy.
As exemplified in Figures 5A,C, only a small fraction (31\%) of wild type LVS were associated with LAMP-1 and the majority of LVS bacteria were found in cytosol by $2 \mathrm{~h}$ post-infection, suggesting successful escape of LVS from the phagosome to cytosol. In sharp contrast, the majority of $\triangle c a p B(61 \%)$ and $\triangle c a p B C A(72 \%)$ were found to be associated with LAMP-1 during the same infection. These LAMP-1 co-localization levels are close to that of inactivated LVS (73\%). Similar to the intracellular growth data (Figure 4B), in trans complementation of $\Delta c a p B$ with the wild type gene on a shuttle plasmid had marginal effect on the LAMP-1 co-localization of the mutant (Figure 5C). This finding thus suggested that $\Delta c a p B$ and $\triangle c a p B C A$ were severely impaired in their ability to escape from the phagosomes into cytosol.

Consistent with the co-localization of both the mutants with LAMP-1, $\Delta c a p B(68 \%)$ and $\triangle c a p B C A(73 \%)$ predominantly colocalized with Cathepsin D, a lysosomal marker, by $2 \mathrm{~h}$ post-infection (Figures 5B,C). As a positive control, only $27 \%$ of live LVS was co-localized with Cathepsin D, which is consistent with its ability to escape from the phagosome-lysosome fusion pathway. In contrast, the inactivated LVS was mostly associated with Cathepsin $\mathrm{D}(83 \%)$ in the same infection period. Similar to the result for LAMP-1 (Figure 5A), the $c a p B$ complementation construct failed to restore the co-localization of $\triangle c a p B$ to the level exhibited by the wild type bacteria (Figures 5B,C). We subsequently confirmed these findings in a $\triangle c a p B$ mutant of $F$. novicida strain U112 (data not shown). These results strongly suggested that $\triangle$ cap $B$ and $\triangle c a p B C A$ are significantly impaired in their ability to arrest maturation of the phagosome.

Finally, we visualized $\Delta c a p B$ and $\triangle c a p B C A$, and their sub-cellular localization in U937 macrophages by transmission electron microscopy. We focused our analysis on the 24 -h time point because the morphology of the infected macrophages was no longer intact beyond this infection period. As represented in Figure 6 (indicated by arrow heads), the LVS-infected cells contained numerous bacteria that appear to be free in the cytoplasm and surrounded by an electron lucent zone. However, in addition to the free bacteria, there were large numbers of partially degraded bacteria in vacuolar-like structures in the macrophages infected with $\Delta c a p B$ (strain ST1092) and $\triangle c a p B C A$ (strain ST938) as indicated by asterisks in Figure 6. This type of sub-cellular structures were rarely found in the LVSinfected macrophages (data not shown). The structures containing apparently degraded bacteria were also readily detectable in the in trans complemented $\Delta c a p B$ (strain ST1104), indicating that the complementation construct failed to restore the impairment in $\triangle c a p B$. These bacterium-containing vacuolar-like structures are likely phagolysosomes or autophagosomes because most of them were surrounded by an identifiable membrane. Taken together, we conclude that the capBCA genes are required for $F$. tularensis phagosomal escape and/or arrest of phagosomal maturation.

\section{DISCUSSION}

The F. tularensis capBCA genes are among the 95 virulence-associated genes identified in our recent STM study (Su et al., 2007). Transposon insertions in each of the capBCA genes resulted in significantly impaired growth of $F$. tularensis LVS in the lungs of $\mathrm{BALB} / \mathrm{c}$ mice 7 days post-intranasal inoculation. In this study, we sought to understand how this gene locus contributes to 

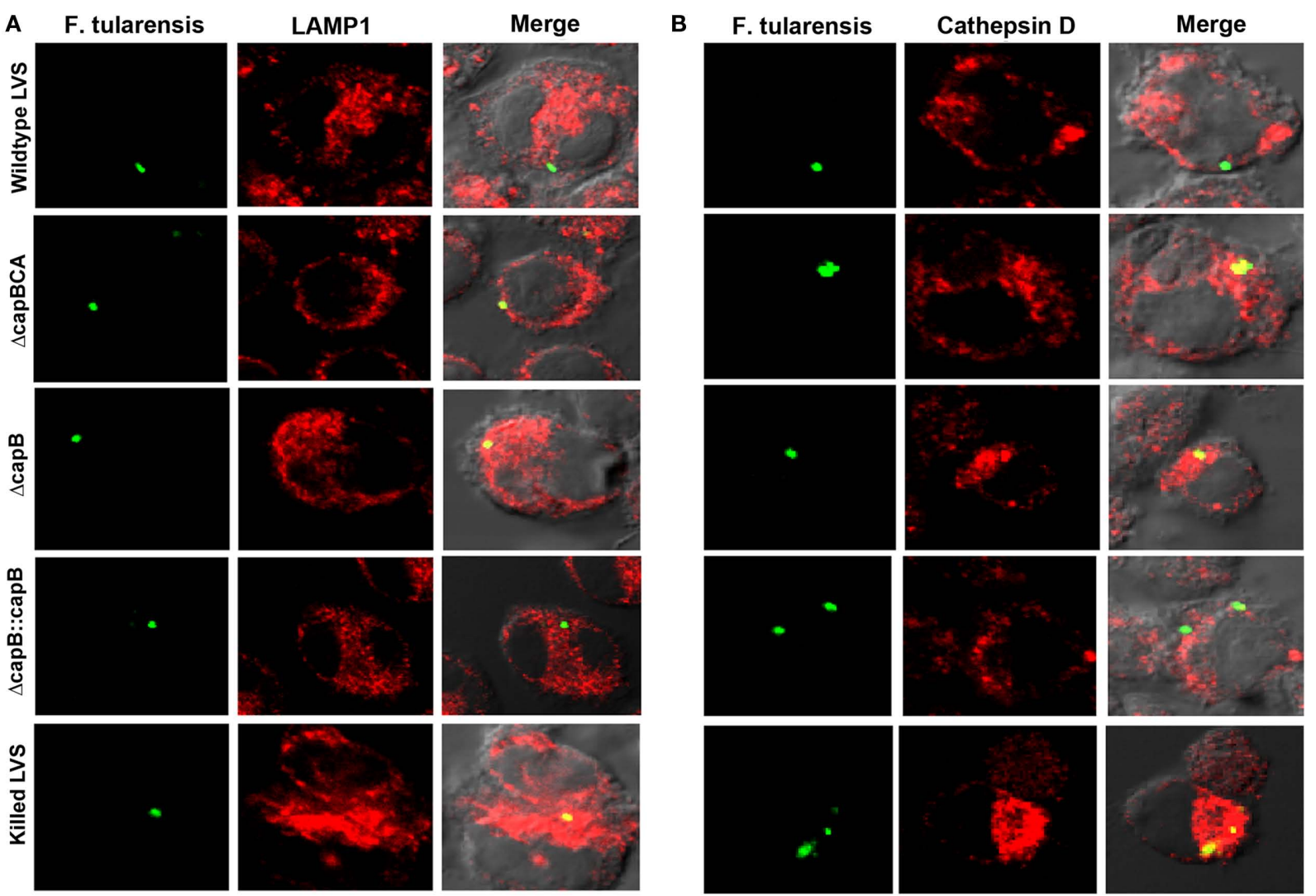

C

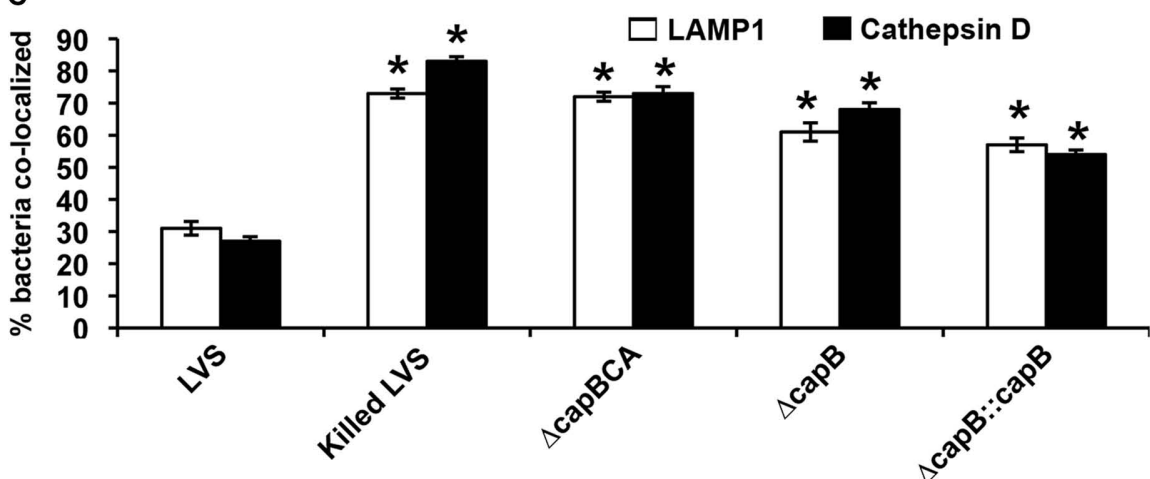

FIGURE 5 | Co-localization of $F$ tularensis capBCA mutants with phagosomal and phagolysosomal markers. (A) Representative images showing co-localization of the LVS capBCA mutants with the phagosomal marker LAMP-1. F. tularensis and LAMP-1 were stained and visualized as described in Section "Materials and Methods." (B) Representative images showing co-localization of the LVS capBCA mutants with phagolysosomal marker Cathepsin D. (C) Association of LVS capBCA mutants with LAMP-1 and Cathepsin D. The results are expressed as the percentage of bacteria co-localized with LAMP-1 or Cathepsin D out of total bacteria in 100 U937 cells. Statistic significance between LVS and its isogenic capBCA mutants $(p>0.05)$ was determined using Student's $t$ test. The data shown are a representative of two independent experiments.
F. tularensis fitness and pathogenesis. Mouse infection experiments demonstrated that the unknown function(s) provided by the $c a p B C A$ genes is required for the fitness and virulence of F. tularensis LVS and human virulent type A strain Schu S4. This finding is consistent with the recent reports that deletion mutants in capB of LVS (Jia et al., 2010) and Schu S4 (Michell et al., 2010) are attenuated in BALB/c mice. The experiments with the LVS capBCA mutants indicated that the capBCA genes are necessary for F. tularensis growth (replication and survival) in target organs at various stages of infection. The results from macrophage infection experiments suggest that the cap $B C A$ genes enhance $F$. tularensis fitness and thus virulence by promoting intracellular growth of the bacterium. This conclusion is supported by significant deficiency of $\triangle c a p B$ and $\triangle c a p B C A$ in intracellular growth in both $\mathrm{MH}-\mathrm{S}$ and $\mathrm{U} 937$ macrophage models. 

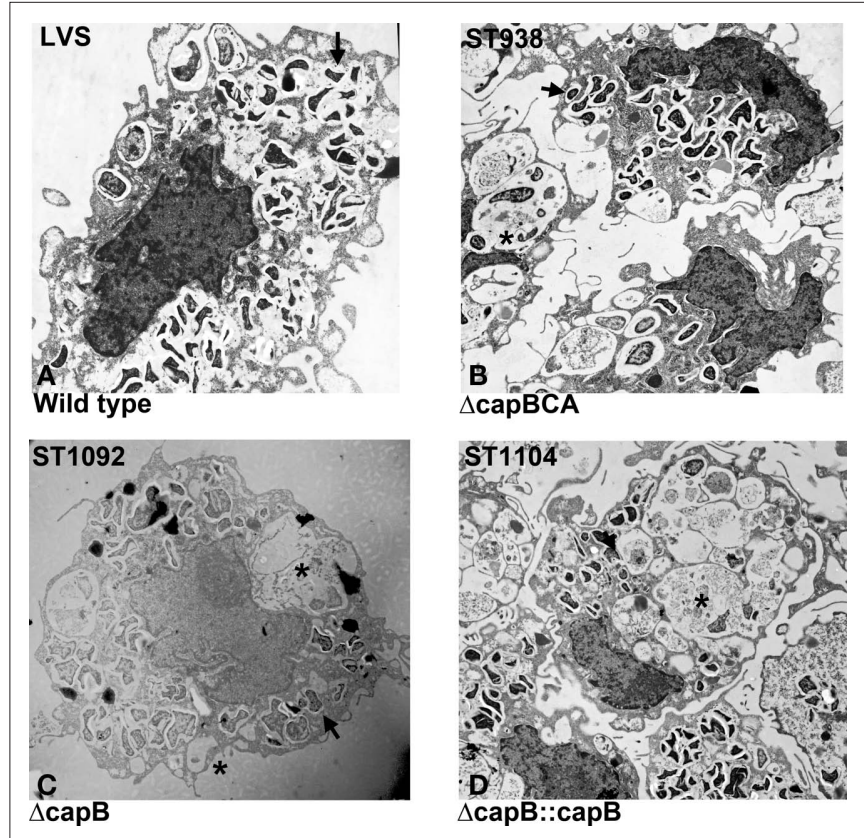

FIGURE 6 | Sub-cellular ultra-structures of U937 macrophages infected by LVS capBCA mutants. Electron micrographs of human macrophages inoculated with $F$. tularensis LVS (A), $\triangle \operatorname{capBCA}$ (ST938) (B), $\triangle \mathrm{capB}$ (ST1092) (C), or complemented $\Delta c a p B$ (ST1104) (D). Indicated are the intact bacteria (arrow heads) and vacuoles containing degraded bacteria (asterisks).

The deficiency of the cap $B C A$ mutants in intracellular growth lies beyond the uptake (attachment/entry) phase of intracellular infection. Specifically, the cap $B C A$ locus appears to enhance the intracellular growth of $F$. tularensis by promoting bacterial escape from phagosomes. This notion is consistent with multiple observations in this study. $\triangle$ cap $B$ and $\triangle c a p B C A$ remained predominantly co-localized with the LAMP-1 (a phagosomal marker) and Cathepsin D (a phagolysosomal marker) in U937 macrophages by $2 \mathrm{~h}$ post-infection. Second, degraded bacteria were abundantly observed in vacuolar-like structures of the macrophages infected with $\triangle c a p B$ and $\triangle c a p B C A$. In this regard, the capBCA mutants behaved similarly to the mutants of other $F$. tularensis genes that are involved in phagosomal escape, most notably, the iglABCD genes located within the Francisella pathogenicity island (FPI; Lai et al., 2004; Nano et al., 2004; Santic et al., 2005b, 2008; de Bruin et al., 2007). However, we noticed that the capBCA mutants were much less impaired than the mutants of iglC or $m g l A$ (encoding a FPI regulator) in terms of intra-macrophage growth (data not shown). While the $i g l C$ or $m g l A$ mutants virtually lacked intra-macrophage growth, the capBCA mutants were still able to grow to a relatively high level under the same conditions (data not shown). This observation indicates that the cap $B C A$ and FPI genes perform distinct functions in terms of promoting intracellular adaptation of $F$. tularensis. In short, it remains to be determined whether the $c a p B C A$ mutants are defective in one or more of the following intracellular infection stages: (i) survival/escape from the phagosomes to the cytosol, (ii) arrest of phagosomal maturation, (iii) replication in the cytosol, and/ or (iv) re-infection of other cells.
It is unclear how the cap $B C A$ genes contribute to $F$. tularensis growth in macrophages and host tissues. F. tularensis CapB and CapC are homologous to the CapB and CapC proteins of Bacillus anthracis, the causative agent of anthrax (Koehler, 2002). CapB and CapC, together with CapA, CapD, and CapE in B. anthracis, are responsible for the biosynthesis of the capsule consisting of poly- $\boldsymbol{\gamma}$-D-glutamic acids (PGA; Candela and Fouet, 2006). CapB, cytoplasmic protein, is the catalytic component of the Bacillus PGA synthesis complex (Troy, 1973). The PGA-based capsule in $B$. anthracis is a major virulence factor due to its antiphagocytic property (Koehler, 2002). Interestingly, recent genome studies have revealed homologs of the PGA biosynthetic genes in a group of highly diverse Gram-negative bacteria including F. tularensis and Fusobacterium nucleatum (Kapatral et al., 2002; Glockner et al., 2003; Ren et al., 2003; Hou et al., 2004; Larsson et al., 2005). Candela et al. (2009) recently reported the production of PGA by the cap$B C A$ genes of $F$. nucleatum. The capBCA loci of $F$. tularensis and $F$. nucleatum are highly similar in gene sequence and order. It is thus possible that the F. tularensis cap BCA locus enhances the bacterial growth in macrophages and host tissues through PGA production. However, no PGA or capsule has been detected from F. tularensis in our preliminary trials (unpublished data) or previous studies (Raynaud et al., 2007; Michell et al., 2010).

The cap $B C A$ locus is highly conserved in genus Francisella. The sequences of the cap $B C A$ coding and intergenic regions are virtually identical among F. tularensis subsp. tularensis (type A) (Larsson et al., 2005; Beckstrom-Sternberg et al., 2007), holarctica (type B) (Chain et al., 2006; Petrosino et al., 2006; Barabote et al., 2009), and novicida (Brittnacher et al., 2007). A recent study also revealed the presence of a similar capBCA locus in Francisella philomiragia (Copeland et al., 2008). Like F. tularensis subsp. novicida, F. philomiragia is a water-associated bacterium and less pathogenic to humans than F. tularensis subsp. tularensis and holarctica (Penn, 2005). Our infection experiments indicate that the cap $B C A$ locus is necessary for the in vivo fitness and full virulence of $F$. tularensis types A and B organisms. Weiss et al. (2007) also showed that the transposon mutants in the capB and capC genes of F. tularensis subsp. novicida are attenuated in a systemic infection mouse model. Considering that mammals may not be the natural reservoirs of $F$. tularensis (Oyston and Quarry, 2005), the uncharacterized function(s) of the cap BCA locus in F. tularensis and perhaps other Francisella species may be evolutionarily selected for a survival advantage under nonmammalian conditions.

It is noticeable that the attenuation level of the Schu S4 $\triangle$ cap $B C A$ mutant was significantly lower than that of the LVS counterpart in our intranasal infection model in BALB/c mice. This difference may be due to other Schu S4-specific factor(s) that might have overshadowed the impact of the capBCA locus in the mouse model. Laboratory mice are exceptionally susceptible to Schu S4 infection (Rick Lyons and Wu, 2007). Alternatively, the capBCA locus operates in a different manner at the transcriptional and/or post-transcriptional level. Lindgren et al. (2007) recently reported that a deletion in the catalase-encoding kat $G$ of $F$. tularensis LVS led to significant attenuation in virulence, but a similar Schu S4 $\Delta k a t G$ mutant showed no attenuation in virulence. Finally, different mouse strains and routes of infection have yielded variable outcomes with the F. tularensis capB mutants in terms of virulence 
and immuno-protection. Michell et al. (2010) reported more than 100-fold attenuation with an Schu S4 capB mutant following subcutaneous inoculation of $\mathrm{BALB} / \mathrm{c}$ mice, whereas no significant attenuation was observed with an independent Schu S4 capB mutant when $\mathrm{BALB} / \mathrm{c}$ mice were infected by aerosol inoculation (Conlan et al., 2010). Further evaluation of the $c a p B C A$ mutants in other animal models is warranted to conclusively define the contribution of this gene locus to $F$. tularensis infection in humans.

\section{REFERENCES}

Ahlund, M. K., Ryden, P., Sjostedt, A., and Stoven, S. (2010). Directed screen of Francisella novicida virulence determinants using Drosophila melanogaster. Infect. Immun. 78, 3118-3128.

Ancuta, P., Pedron, T., Girard, R., Sandstrom, G., and Chaby, R. (1996). Inability of the Francisella tularensis lipopolysaccharide to mimic or to antagonize the induction of cell activation by endotoxins. Infect. Immun. 64, 2041-2046.

Anthony, L. S., and Kongshavn, P. A. (1987). Experimental murine tularemia caused by Francisella tularensis, live vaccine strain: a model of acquired cellular resistance. Microb. Pathog. 2, 3-14.

Anthony, L. S. D., Burke, R. D., and Nano, F. E. (1991). Growth of Francisella spp. in rodent macrophages. Infect. Immun. 59, 3291-3296.

Asare, R., and Abu Kwaik, Y. (2010). Molecular complexity orchestrates modulation of phagosome biogenesis and escape to the cytosol of macrophages by Francisella tularensis. Environ. Microbiol. 12, 2559-2586.

Barabote, R. D., Xie, G., Brettin, T. S., Hinrichs, S. H., Fey, P. D., Jay, J. J., Engle, J. L., Godbole, S. D., Noronha, J. M., Scheuermann, R. H., Zhou, L. W., Lion, C., and Dempsey, M. P. (2009). Complete genome sequence of Francisella tularensissubspecies holarctica FTNF002-00. PLoSOne 4, e7041. doi: 10.1371/journal.pone.0007041

Barker, J. R., and Klose, K. E. (2007). Molecular and genetic basis of pathogenesis in Francisella tularensis. Ann. N. Y. Acad. Sci. 1105, 138-159.

Baron, G. S., and Nano, F. E. (1998). $\mathrm{MglA}$ and $\mathrm{MglB}$ are required for the intramacrophage growth of Francisella novicida. Mol. Microbiol. 29, 247-259.

Baron, S. D., Singh, R., and Metzger, D. W. (2007). Inactivated Francisella tularensis live vaccine strain protects against respiratory tularemia by intranasal vaccination in an immunoglobulin A-dependent fashion. Infect. Immun. 75, 2152-2162.

Beckstrom-Sternberg, S. M., Auerbach, R. K., Godbole, S., Pearson, J. V.,
Beckstrom-Sternberg, J. S., Deng, Z., Munk, C., Kubota, K.,Zhou,Y.,Bruce, D., Noronha, J., Scheuermann, R.H., Wang, A., Wei, X., Wang, J., Hao, J., Wagner, D. M., Brettin, T.S., Brown, N., Gilna,P., and Keim, P. S. (2007). Complete genomic characterization of a pathogenic A.II strain of Francisella tularensis subspecies tularensis. PLoS ONE 2, e947. doi: 10.1371/journal.pone.0000947

Bonquist, L., Lindgren, H., Golovliov, I., Guina, T., and Sjostedt, A. (2008). MglA and Igl proteins contribute to the modulation of Francisella tularensis live vaccine strain-containing phagosomes in murine macrophages. Infect. Immun. 76, 3502-3510. Abmayr, S., D’Argenio, D., Bovee, D., Chang, J., Chen, J., Drees, B., Ernst, R., Fong, C., Forsman, M., Gallagher, L., Gallis, B., Gillett, W., Goodlett, D., Guina, T., Guenthner, D., Haugen, E., Hayden, H., Jacobs, M., Kang, A., Manoil, C., Olson, M.V., Radey, M., Shaffer, S., Svensson, K., Taylor, G., Wasnick, M., Kaul, R., and Miller, S.I. (2007). Francisella tularensis subsp. novicida U112, complete genome. GenBank accession CP000439.

Buchan, B. W., McCaffrey, R. L., Lindemann, S. R., Allen, L. A., and Jones, B. D. (2009). Identification of migR, a regulatory element of the Francisella tularensis live vaccine strain iglABCD virulence operon required for normal replication and trafficking in macrophages. Infect. Immun. 77, 2517-2529.

Candela, T., and Fouet, A. (2006). Polygamma-glutamate in bacteria. Mol. Microbiol. 60, 1091-1098.

Candela, T., Moya, M., Haustant, M., and Fouet, A. (2009). Fusobacterium nucleatum, the first Gram-negative bacterium demonstrated to produce polyglutamate. Can. J. Microbiol. 55, 627-632.

Chain, P., Larimer, F., Land, M., Stilwagen, S., Larsson, P., Bearden, S., Chu, M., Oyston, P., Forsman, M., Andersson, S., Lindler, L., Titball, R., and Garcia, E. (2006). Francisella tularensis subsp. holarcticastrain LVS complete genome. GenBank accession AM233362.
Brittnacher, M., Rohmer, L., Zhou, Y., Larson Freeman, T., Levy, R., Lim, R.,

\section{ACKNOWLEDGMENTS}

This work was supported by the Tsinghua University Support Fund (Jing-Ren Zhang), the Chinese Universities Scientific Fund No. 2009-3-03 (Jingliang Su), Commonwealth of Kentucky Research Challenge Trust Fund (Yousef Abu-Kwaik), and NIH grants R21AI083963 (Jing-Ren Zhang), P01AI056320 (Jing-Ren Zhang), R01AI43965 (Yousef Abu-Kwaik), and R01AI069321 (Yousef Abu-Kwaik).

Charity, J. C., Costante-Hamm, M. M., Balon, E. L., Boyd, D. H., Rubin, E. J., and Dove, S. L. (2007). Twin RNA polymerase-associated proteins control virulence gene expression in Francisella tularensis. PLoS Pathog. 3, e84. doi: 10.1371/journal.ppat.0030084

Checroun, C., Wehrly, T. D., Fischer, E. R., Hayes, S. F., and Celli, J. (2006). Autophagy-mediated reentry of Francisella tularensis into the endocytic compartment after cytoplasmic replication. Proc. Natl.Acad.Sci. U.S.A. 103, 14578-14583.

Clemens, D. L., and Horwitz, M. A (2007). Uptake and intracellular fate of Francisella tularensis in human macrophages. Ann. N. Y. Acad. Sci. 1105, 160-186.

Clemens, D. L., Lee, B. Y., and Horwitz, M. A. (2004). Virulent and avirulent strains of Francisella tularensis prevent acidification and maturation of their phagosomes and escape into the cytoplasm in human macrophages. Infect. Immun. 72, 3204-3217.

Clemens, D. L., Lee, B. Y., and Horwitz, M. A. (2005). Francisella tularensis enters macrophages via a novel process involving pseudopod loops. Infect. Immun. 73, 5892-5902.

Conlan, J. W., Shen, H., Golovliov, I., Zingmark, C., Oyston, P. C., Chen, W., House, R. V., and Sjostedt, A. (2010). Differential ability of novel attenuated targeted deletion mutants of Francisella tularensis subspecies tularensis strain SCHU S4 to protect mice against aerosol challenge with virulent bacteria: effects of host background and route of immunization. Vaccine 28, 1824-1831.

Copeland, A., Lucas, S., Lapidus, A., Barry, K., Detter, J. C., Glavina del Rio, T., Hammon, N., Israni, S., Dalin, E., Tice, H., Pitluck, S., Chain, P., Malfatti, S., Shin, M., Vergez, L. Schmutz, J., Larimer, F., Land, M., Hauser, L., and Richardson, P. (2008). Complete sequence of chromosome of Francisella philomiragia subsp. philomiragia ATCC 25017. GenBank accession NC 010336.

de Bruin, O. M., Ludu, J. S., and Nano, F. E. (2007). The Francisella pathogenicity island protein IglA localizes to the bacterial cytoplasm and is needed for intracellular growth. BMC Microbiol. 7, 1. doi: 10.1186/1471-2180-7-1

Dennis, D. T., Inglesby, T. V., Henderson, D. A., Bartlett, J. G., Ascher, M. S. Eitzen, E., Fine, A. D., Friedlander, A. M., Hauer, J., Layton, M., Lillibridge, S. R., McDade, J. E., Osterholm, M T., O’Toole, T., Parker, G., Perl, T. M., Russell, P. K., Tonat, K., and Working Group on Civilian Biodefense. (2001). Tularemia as a biological weapon: medical and public health management. JAMA 285, 2763-2773.

Duckett, N. S., Olmos, S., Durrant, D. M., and Metzger, D. W. (2005). Intranasal interleukin-12 treatment for protection against respiratory infection with the Francisella tularensis live vaccine strain. Infect. Immun. 73, 2306-2311.

Eigelsbach, H. T., Braun, W., and Herring, R. D. (1951). Studies on the variation of Bacterium tularense. J. Bacteriol.61, 557-569.

Eigelsbach, H. T., and Downs, C. M. (1961). Prophylactic effectiveness of live and killed tularemia vaccines. I. Production of vaccine and evaluation in the white mouse and guinea pig. $J$. Immunol. 87, 415-425.

Fortier, A. H., Green, S. J., Polsinelli, T., Jones, T. R., Crawford, R. M., Leiby, D. A., Elkins, K. L., Meltzer, M. S., and Nacy, C. A. (1994). "Life and death of an intracellular pathogen: Francisella tularensis and the macrophage," in Macrophage-Pathogen Interactions, eds B. S. Zwilling, and T. K. Eisenstein (New York: Marcel Dekker, Inc.), 349-361.

Glockner, F. O., Kube, M., Bauer, M., Teeling, H., Lombardot, T., Ludwig, W., Gade, D., Beck, A., Borzym, K., Heitmann, K., Rabus, R., Schlesner, H., Amann, R., and Reinhardt R. (2003). Complete genome sequence of the marine planctomycete Pirellula sp. strain 1. Proc. Natl. Acad. Sci. U.S.A. 100, 8298-8303.

Golovliov, I., Baranov, V., Krocova, Z., Kovarova, H., and Sjostedt, A. (2003). An attenuated strain of the facultative intracellular bacterium Francisella tularensis can escape the phagosome of monocytic cells. Infect. Immun. 71, 5940-5950. 
Hou, S., Saw, J. H., Lee, K. S., Freitas, T. A., Belisle, C., Kawarabayasi, Y., Donachie, S. P., Pikina, A., Galperin, M. Y., Koonin, E. V., Makarova, K. S., Omelchenko, M. V., Sorokin, A., Wolf, Y. I., Li, Q. X., Keum, Y. S., Campbell, S., Denery, J., Aizawa, S., Shibata, S., Malahoff, A., and Alam, M. (2004). Genome sequence of the deep-sea $\gamma$-proteobacterium Idiomarina loihiensis reveals amino acid fermentation as a source of carbon and energy. Proc. Natl. Acad. Sci. U.S.A. 101, 18036-18041.

Ibrahim-Granet, O., Philippe, B., Boleti, H., Boisvieux-Ulrich, E., Grenet, D., Stern, M., and Latge, J. P. (2003). Phagocytosis and intracellular fate of Aspergillus fumigatus conidia in alveolar macrophages. Infect. Immun. 71, 891-903.

Jia, Q., Lee, B. Y., Bowen, R., Dillon, B. J., Som, S. M., and Horwitz, M.A. (2010). A Francisella tularensis live vaccine strain (LVS) mutant with a deletion in capB, encoding a putative capsular biosynthesis protein, is significantly more attenuated than LVS yet induces potent protective immunity in mice against $F$. tularensis challenge. Infect. Immun. 78, 4341-4355.

Kadzhaev, K., Zingmark, C., Golovliov, I., Bolanowski, M., Shen, H., Conlan, W. and Sjostedt, A. (2009). Identification of genes contributing to the virulence of Francisella tularensis SCHU S4 in a mouse intradermal infection model. PLoS ONE 4, e5463. doi: 10.1371/ journal.pone.0005463

Kapatral, V., Anderson, I., Ivanova, N., Reznik, G., Los, T., Lykidis, A., Bhattacharyya, A., Bartman, A., Gardner, W., Grechkin, G., Zhu, L., Vasieva, O., Chu, L., Kogan, Y., Chaga, O., Goltsman, E., Bernal, A., Larsen, N., D'Souza, M., Walunas, T., Pusch, G., Haselkorn, R., Fonstein, M., Kyrpides, N., and Overbeek, R. (2002). Genome sequence and analysis of the oral bacterium Fusobacterium nucleatum strain ATCC 25586. J. Bacteriol. 184, 2005-2018.

Keim, P., Johansson, A., and Wagner, D. M. (2007). Molecular epidemiology, evolution, and ecology of Francisella. Ann. N. Y. Acad. Sci. 1105, 30-66.

Koehler, T. M. (2002). Bacillus anthracis genetics and virulence gene regulation. Curr. Top. Microbiol. Immunol. $271,143-164$.

Kraemer, P. S., Mitchell, A., Pelletier, M. R., Gallagher, L. A., Wasnick, M., Rohmer, L., Brittnacher, M. J., Manoil, C., Skerett, S. J., and Salama, N. R. (2009). Genome-wide screen in Francisella novicida for genes required for pulmonary and systemic infection in mice. Infect. Immun. 77, 232-244.
Lai, X. H., Golovliov, I., and Sjostedt, A. (2001). Francisella tularensis induces cytopathogenicity and apoptosis in murine macrophages via a mechanism that requires intracellular bacterial multiplication. Infect. Immun. 69, 4691-4694.

Lai, X. H., Golovliov, I., and Sjostedt, A. (2004). Expression of IglC is necessary for intracellular growth and induction of apoptosis in murine macrophages by Francisella tularensis. Microb. Pathog. 37, 225-230.

Lai, X. H., and Sjostedt, A. (2003). Delineation of the molecular mechanisms of Francisella tularensis-induced apoptosis in murine macrophages. Infect. Immun. 71, 4642-4646.

Larsson, P., Oyston, P. C., Chain, P., Chu, M. C., Duffield, M., Fuxelius, H. H., Garcia, E., Halltorp, G., Johansson, D., Isherwood, K. E., Karp, P. D., Larsson, E., Liu, Y., Michell, S., Prior, J., Prior, R., Malfatti, S., Sjöstedt, A., Svensson, K., Thompson, N., Vergez, L., Wagg, J. K., Wren, B. W., Lindler, L. E., Andersson, S. G., Forsman, M., and Titball, R. W. (2005). The complete genome sequence of Francisella tularensis, the causative agent of tularemia. Nat. Genet. 37, 153-159.

Lindgren, H., Shen, H., Zingmark, C., Golovliov, I., Conlan, W., and Sjostedt, A. (2007). Resistance of Francisella tularensis strains against reactive nitrogen and oxygen species with special reference to the role of KatG. Infect. Immun. 75, 1303-1309.

LoVullo, E. D., Sherrill, L. A., Perez, L. L., and Pavelka, M. S. Jr. (2006). Genetic tools for highly pathogenic Francisella tularensis subsp. tularensis. Microbiology 152, 3425-3435.

Lu, L., Ma, Y., and Zhang, J. R. (2006). Streptococcus pneumoniae recruits complement factor $\mathrm{H}$ through the amino terminus of CbpA. J. Biol. Chem. 281, 15464-15474.

Maier, T. M., Casey, M. S., Becker, R. H., Dorsey, C.W., Glass, E. M., Maltsev, N., Zahrt, T. C., and Frank, D. W. (2007) Identification of Francisella tularensis Himar1-based transposon mutants defective for replication in macrophages. Infect. Immun. 75, 5376-5389.

Makino, S., Uchida, I., Terakado, N., Sasakawa, C., and Yoshikawa, M. (1989). Molecular characterization and protein analysis of the cap region, which is essential for encapsulation in Bacillus anthracis. J. Bacteriol. 171, 722-730.

Malik, M., Bakshi, C. S., McCabe, K., Catlett, S. V., Shah, A., Singh, R., Jackson, P. L., Gaggar, A., Metzger, D. W., Melendez, J. A., Blalock, J. E., and Sellati, T. J. (2007). Matrix metalloproteinase 9 activity enhances host susceptibility to pulmonary infection with type A and B strains of Francisella tularensis. J. Immunol. 178, 1013-1020.

Mbawuike, I. N., and Herscowitz, H. B. (1989). MH-S, a murine alveolar macrophage cell line: morphological, cytochemical, and functional characteristics. J. Leukoc. Biol. 46, 119-127.

McCrumb, F. R. (1961). Aerosol infection of man with Pasteurella tularensis. Bacteriol. Rev. 25, 262-267.

Michell, S. L., Dean, R. E., Eyles, J. E., Hartley, M. G., Waters, E., Prior, J. L., Titball, R. W., and Oyston, P.C. (2010). Deletion of the Bacillus anthracis capB homologue in Francisella tularensi subspecies tularensis generates an attenuated strain that protects mice against virulent tularaemia. J. Med. Microbiol. 59, 1275-1284.

Mohapatra, N. P., Balagopal, A., Soni, S., Schlesinger, L. S., and Gunn, J. S. (2007). AcpA is a Francisella acid phosphatase that affects intramacrophage survival and virulence. Infect. Immun. 75, 390-396.

Nano, F. E., Zhang, N., Cowley, S. C., Klose, K. E., Cheung, K. K., Roberts, M. J., Ludu, J. S., Letendre, G. W. Meierovics, A. I., Stephens, G., and Elkins, K. L. (2004). A Francisella tularensis pathogenicity island required for intramacrophage growth. J. Bacteriol. 186, 6430-6436.

Oyston, P. C., and Quarry, J. E. (2005). Tularemia vaccine: past, present and future. Antonie Van Leeuwenhoek 87, 277-281.

Penn, R. L. (2005). “Francisella tularensis" in Principles and Practice of Infectious Diseases, eds G. L. Mandell, J. E. Bennett, and R. D. Dolin (New York: Churchill Livingstone), 2674-2685.

Petrosino, J. F., Xiang, Q., Karpathy, S. E., Jiang, H., Yerrapragada, S., Liu, Y., Gioia, J., Hemphill, L., Gonzalez, A., Raghavan, T. M., Uzman, A., Fox, G. E., Highlander, S., Reichard, M. Morton, R. J., Clinkenbeard, K. D., and Weinstock, G.M. (2006).Chromosome rearrangement and diversification of Francisella tularensis revealed by the type B (OSU18) genome sequence. $J$. Bacteriol. 188, 6977-6985.

Qin, A., and Mann, B. J. (2006). Identification of transposon insertion mutants of Francisella tularensis tularensis strain Schu S4 deficient in intracellular replication in the hepatic cell line HepG2. BMC Microbiol. 6, 69 . doi: 10.1186/1471-2180-6-69

Raynaud, C., Meibom, K. L., Lety, M. A., Dubail, I., Candela, T., Frapy, E. and Charbit, A. (2007). Role of the wbt locus of Francisella tularensis in lipopolysaccharide $\mathrm{O}$-antigen biogenesis and pathogenicity. Infect. Immun. $75,536-541$.
Ren, S. X., Fu, G., Jiang, X. G., Zeng, R., Miao, Y. G., Xu, H., Zhang, Y. X., Xiong, H., Lu, G., Lu, L. F., Jiang, H. Q., Jia, J., Tu, Y. F., Jiang, J. X., Gu, W. Y., Zhang, Y. Q., Cai, Z., Sheng, H. H., Yin, H. F., Zhang, Y., Zhu, G. F., Wan, M., Huang, H. L., Qian, Z., Wang, S. Y., Ma, W., Yao, Z. J., Shen, Y., Qiang, B. Q., Xia, Q. C., Guo, X. K., Danchin, A., Saint Girons, I., Somerville, R. L., Wen, Y. M., Shi, M. H., Chen, Z., Xu, J. G., and Zhao, G. P. (2003). Unique physiological and pathogenic features of Leptospira interrogans revealed by whole-genome sequencing. Nature 422, 888-893.

Rick Lyons, C., and Wu, T. H. (2007) Animal models of Francisella tularensis infection. Ann. N. Y. Acad. Sci. 1105, 238-265.

Sandstrom, G., Sjostedt, A., Johansson, T., Kuoppa, K., and Williams, J. C. (1992). Immunogenicity and toxicity of lipopolysaccharide from Francisella tularensis LVS. FEMS Microbiol. Immunol. 5, 201-210.

Santic, M., Asare, R., Skrobonja, I., Jones, S., and Abu Kwaik, Y. (2008). Acquisition of the vacuolar ATPase proton pump and phagosome acidification are essential for escape of Francisella tularensis into the macrophage cytosol. Infect. Immun. 76, 2671-2677.

Santic, M., Khodor, S. A., and Kwaik, Y. A. (2010). Cell biology and molecular ecology of Francisella tularensis. Cell. Microbiol. 12, 129-139.

Santic, M., Molmeret, M., and Abu Kwaik, Y. (2005a). Modulation of biogenesis of the Francisella tularensis subsp. novicida-containing phagosome in quiescent human macrophages and its maturation into a phagolysosome upon activation by IFN-gamma. Cell. Microbiol. 7, 957-967.

Santic, M., Molmeret, M., Klose, K. E., Jones, S., and Kwaik, Y. A. (2005b). The Francisella tularensis pathogenicity island protein IglC and its regulator MglA are essential for modulating phagosome biogenesis and subsequent bacterial escape into the cytoplasm. Cell. Microbiol. 7, 969-979.

Schulert, G. S., McCaffrey, R. L., Buchan, B. W., Lindemann, S. R., Hollenback, C., Jones, B. D., and Allen, L. A. (2009). Francisella tularensis genes required for inhibition of the neutrophil respiratory burst and intramacrophage growth identified by random transposon mutagenesis of strain LVS. Infect. Immun. 77, 1324-1336.

Sjostedt, A. (2007). Tularemia: history, epidemiology, pathogen physiology, and clinical manifestations. Ann. N. Y. Acad. Sci. 1105, 1-29. 
Su, J., Yang, J., Zhao, D., Kawula, T. H., Banas, J. A., and Zhang, J.-R. (2007). Genome-wide identification of Francisella tularensis virulence determinants. Infect. Immun. 75, 3089-3101.

Sun, K., Johansen, F. E., Eckmann, L., and Metzger, D. W. (2004). An important role for polymeric Ig receptor-mediated transport of IgA in protection against Streptococcus pneumoniae nasopharyngeal carriage. J. Immunol. 173, 4576-4581.

Tempel, R., Lai, X. H., Crosa, L., Kozlowicz, B., and Heffron, F. (2006). Attenuated Francisella novicida transposon mutants protect mice against wild-type challenge. Infect. Immun. 74, 5095-5105.
Troy, F. A. (1973). Chemistry and biosynthesis of the poly(-D-glutamyl) capsule in Bacillus licheniformis. II. Characterization and structural properties of the enzymatically synthesized polymer. J. Biol. Chem. 248, 316-324.

Weiss, D. S., Brotcke, A., Henry, T., Margolis, J. J., Chan, K., and Monack, D. M. (2007). In vivo negative selection screen identifies genes required for Francisella virulence. Proc. Natl. Acad. Sci. U.S.A. 104, 6037-6042.

Wilson, C. B., Tsai, V., and Remington, J. S. (1980). Failure to trigger the oxidative metabolic burst by normal macrophages. Possible mechanism for survival of intracellular pathogens. $J$. Exp. Med. 151, 328-346.

Zhang, J.-R., Hardham, J. M., Barbour, A. G., and Norris, S. J. (1997). Antigenic variation in Lyme disease borreliae by promiscuous recombination of VMP-like sequence cassettes. Cell 89, 275-285.

Conflict of Interest Statement: The authors declare that the research was conducted in the absence of any commercial or financial relationships that could be construed as a potential conflict of interest.

Received: 09 December 2010; accepted: 07 April 2011; published online: 25 April 2011.
Citation: Su J, Asare R, Yang J, Nair MKM, MazurkiewiczJE, Abu-Kwaik Y and Zhang $J-R$ (2011) The capBCA locus is required for intracellular growth of Francisella tularensis LVS. Front. Microbio. 2:83. doi: 10.3389/fmicb.2011.00083

This article was submitted to Frontiers in Cellular and Infection Microbiology, a specialty of Frontiers in Microbiology.

Copyright () 2011 Su, Asare, Yang, Nair, Mazurkiewicz, Abu-Kwaik and Zhang. This is an open-access article subject to a non-exclusive license between the authors and Frontiers MediaSA, which permits use, distribution and reproduction in other forums, provided the original authors and source are credited and other Frontiers conditions are complied with. 


\section{APPENDIX}
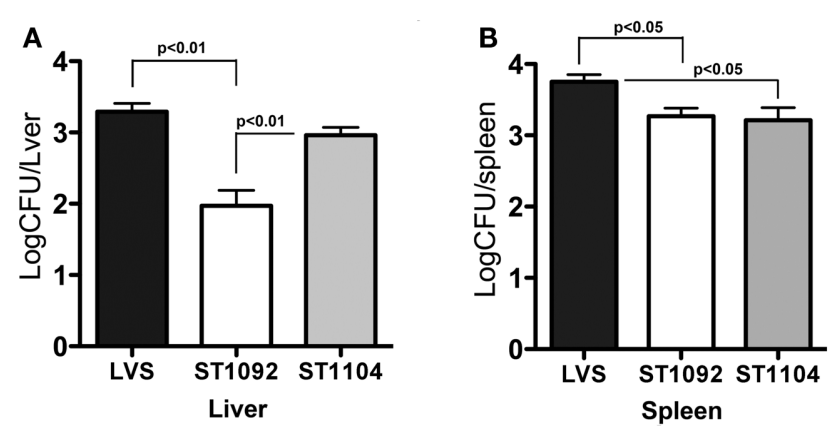

FIGURE A1 | In vivo growth of the $F$ tularensis $\Delta$ capB mutants in the livers (A) and spleens (B) of BALB/c mice. BALB/c mice were infected individually with LVS (4,500 CFUs), ST1092 (5,100 CFUs), or ST1104

(4,800 CFUs) by intranasal inoculation. Bacterial levels in the livers and spleens were assessed at day 7 as in Figure 3. 